\section{América Latina y el nuevo Renminbi}

\section{Por Juan Foxley Rioseco}
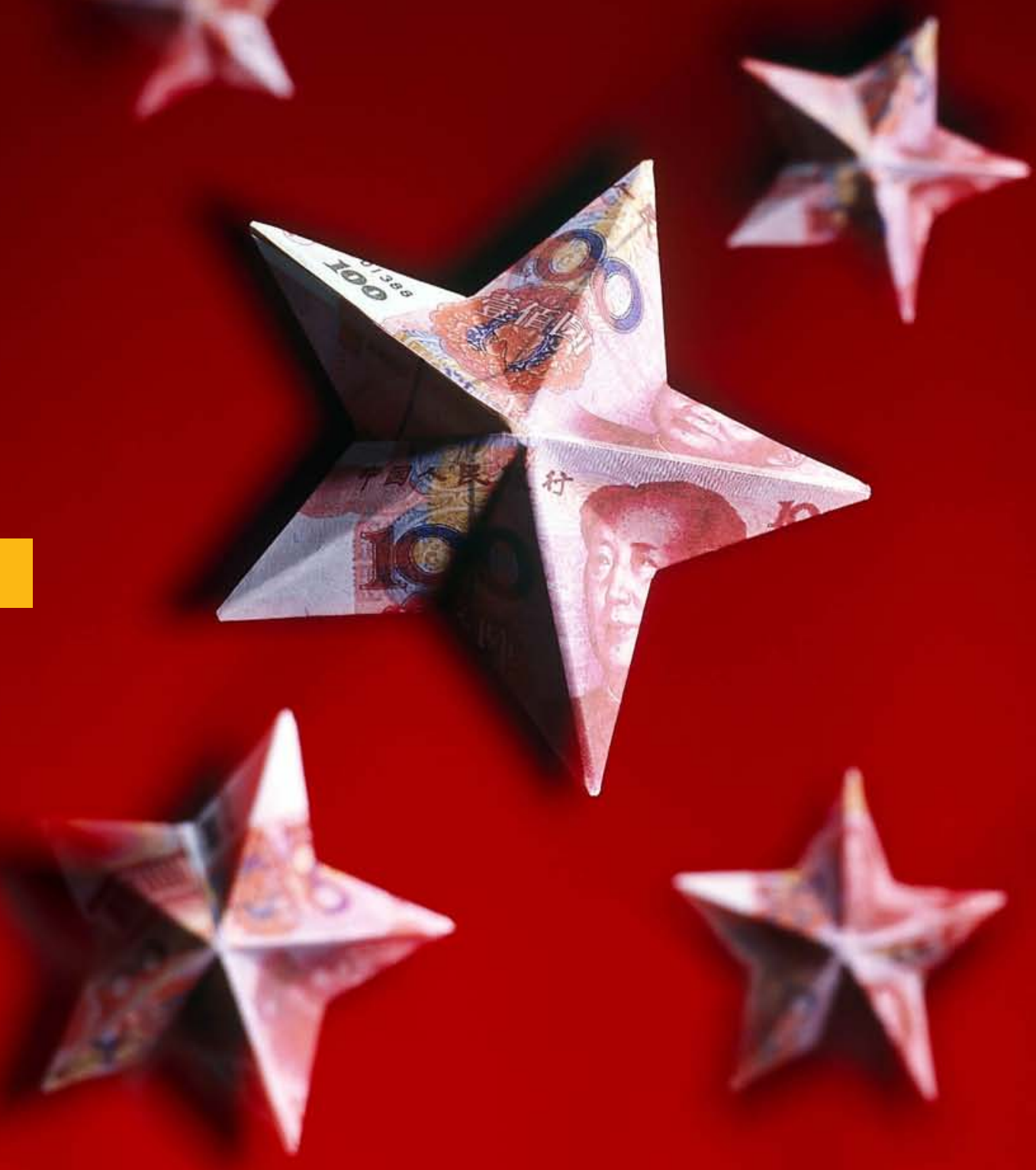

No deja de sorprender la rapidez con que cos alcanzaba el equivalente a $\$ 93.000$ la moneda china comienza a ser utilizada internacionalmente. Desde cero participación en 2008, la facturación denominada en Renminbi (RMB) hoy ya alcanza a más del $8 \%$ del total del co-
mercio exterior chino. No es usual que un pais in

su moneda antes de abrise a los flujos de capital. Sin embargo, y como resultado de sucesivas flexibilizaciones, las autoridades han logrado que el RMB ("moneda del pueblo" en su traducción literal)- comience a acompanarar no sol su comercio exterior de bienes y servicios, sino también operaciones de préstamos, hir Ciertamen

la moneda propia nacionalización chovinismo si los socios comerciales de China no apreciaran ventajas palpables en transarla o mantenerla. Si un
exportador, importador o inversionista exportador, importador o inversionista
escoge saldar sus pagos en moneda ch na es porque, primero, al remplazar moneda de un tercer pais podra dejar de los tipos de cambio $Y$ si sigue haciondonegocios en dólares de Estados Unidos otra moneda ajena, el riesgo termina castigando de una u otra forma el precio de sus productos. Segundo, al operar en RMB podrá ahorrar los costos de transaccion involucrados en cada transferencia. Por ultimo, en el caso de inversionistas institucionales, la potenci ventaja de diversificar monedas deber
ser evidente.

Como se sabe, la principal unidad de RMB, el yuan, no es convertible libremente en el continente (CNY). Sin embargo, desde 2010, las autoridades bastantes menos restricciones dentro de Hong Kong, creando el espacio para un
activo mercado de RMB off-shore (CNH) activo mercado de RMB off-shore (CNH), En la pràctica esta "nueva moneda", es
convertible para la mayor parte de las transacciones excepto cuando estas inpliquen entradas de capital a China continental.

El mercado de CNH ha ido aumentando su liquidez. Hacia fines de 2011,
saldo de depósitos mantenido en bandel ultimo mes del año (5) equivalentes en CNH. Bl mercado es alla retención de exportadores extranjeros que operan en Hong Kong, las compras de ciudadanos de la China continental las transacciones transfronterizas de empresas importadoras y exportadoras junto con los inversionistas institucionales calificados, han sido autorizadas a hacerlo.

a los volúmenes crecientes de comercio bilateral, conocer el meren la a de todo directivo latinoamericano.

Entre 2000 y 2009, la participación de China como destino pasó de 1,1\% 11,90 del total importado). No en vano del total importado). No en vano, citada como factor clave en la rápida ecuperación de varios paises de la re2008. En alo de la crisis de crédito de de comercio han sido notables, como lo muestran datos de la CEPAL: las expor(aciones a China desde Brasil pasaron de al $13,2 \%$; desde Chile de $5,0 \%$ a de los totales respectivos durante la dé cada. A su turno, en el mismo período, las importaciones desde China subieron Paraguay desde el 11,4\% al $13,9 \% \mathrm{y}$, Además del com cios, China empieza a mostrar presencia en la inversión en infraestructura, transporte, energia y defensa. Se sabe por ejemplo, de las intenciones chinas de construir una conexion ferroviaria alternativa al canal de Panamá a traves de el gas argentino. En la medida que los co mano de obra sigan aumencrecer y extenderse haci la ma deberiara y otros sectores donde varios paises de América Latina pueden servir de puente tas latinoamericanos han comenzado a diversificar sus carteras para incluir RMB en sus carteras. Por ejemplo, mas Che de Co11. A rivel global, tanda a fines de los fondos sobranos y de perions de diversos países. Fl de Corea del Sur, por ejemplo, anunció recién que aumentará cuota en China por sobre los USD 100 illones actuales.

ys depositos y los bonos del gobierno y empresas (Dim Sum Market), son los actor to requieren ninguna autoncoco mecesitan tence prosencios, thimy no existen impuestos a bo intreses i a las ranancias de capital. El Banco Mundial y el Banco de Desarrollo Asiático han colocado en Hong Kong emisioes de bonos denominadas en moned hina. También lo han hecho compa-
ias como McDonald's, Unilever, BP, olkswagen y Tesco.

De esta manera, se están presentando riesgo de monedas en el comercio exterior, también de diversificar activos fnancieros, y eventualmente, tomar posiciones sobre la base de las propias expectativas respecto de la tasa de cambio. Por ahora, los mercados de $\mathrm{CNY}$ y CNH no permiten el arbitraje ya que existe un conjunto de regulaciones que restringe la entrada de RMB al continente. Sin pmbargo, ninguna de ellas es obstácul ara el con dosde Latino Pórica, a ningín inversioista debería extrañarle observar restricciones a los ingresos de capitales que, unque en menor grado, han utilizado Brasil y Chile en diferentes períodos en que intentaban atenuar la volatilida externa provocada por los "capitales go-

En cambio, lo relevante a observar hoy que, mintas al mercado del CN hacer negocios con China tienen a Icance cada vez mejores herramientas financieras para un comercio más eficiente y menos expuesto a los riesgos cambiarios. 